\title{
Enhanced production of fructose ester by biocatalyzed continuous flow process
}

\author{
Felipe K Sutili ${ }^{1}$, Halliny S Ruela ${ }^{1}$, Daniel De O Nogueira ${ }^{1,2}$, Ivana CR Leal ${ }^{2}$, Leandro SM Miranda ${ }^{1}$ \\ and Rodrigo OMA De Souza ${ }^{1^{*}}$
}

\begin{abstract}
Background: Fatty acid sugar esters are non-toxic, odorless, non-irritanting surfactants. They can be synthesized by renewable resources and are completely biodegradable in aerobic and anaerobic conditions. Their application has been expanded in innumerous areas including pharmaceuticals, cosmetics, detergents and food industry. Lipase-catalyzed esterification have been investigated as a potential substitute to the traditional chemical, demanding milder reaction conditions, allowing better reaction control and providing higher-quality products. So, the lipase catalyzed sugar ester synthesis becomes an interesting strategy for producing biodegradable, non- ionic surfactants. The main disadvantage of this protocol is the poor solubility of substrates and long reaction time required for performed the esterification reaction with moderated to good yields.
\end{abstract}

Results: Here in, we report the enzymatic esterification of steric hindered fructose derivative with free fatty acids derived from palm oil refining process (RePO) under continuous flow conditions at concentrations up to $0.5 \mathrm{M}$, increasing the productivity up to $100 \mathrm{mg}$. $\mathrm{min}^{-1} . \mathrm{g}$ immob. enzyme ${ }^{-1}$.

Conclusions: The immobilized commercial enzyme from Rhizomucor miehei generated the best performance between the catalysts tested.

\section{Background}

Sugar esters derived from fatty acids are a very interesting class of surfactants with wide application in industry $[1,2]$. These esters can be applied in innumerous areas including pharmaceuticals, cosmetics, detergents and food industry [3], because of their wide range of hydrophilic/lipophilic balance (HLB) depending on the length of the fatty acid chain and the nature of the sugar [4].

Fructose based surfactants possess good interfacial tension values when compared with commercial sucrose esters [5]. Despite all importance related to this class of molecules, the synthesis of fructose esters is still a challenging task. Most of the chemical process used to the synthesis of these molecules uses mineral or heterogeneous solid acids, under mild conditions in order to preserve the sugar moiety, leading to moderate conversions and colored products; often a mixture of mono-, di-ester is produced, after long reaction times [6]. Lipase-catalyzed

\footnotetext{
* Correspondence: rodrigosouza@iq.ufrj.br

1 Biocatalysis and Organic Synthesis Group, Chemistry Institute, Federal University of Rio de Janeiro, Rio de Janeiro CEP 22941 909, Brazil Full list of author information is available at the end of the article
}

protocols have already been used to overcome the drawbacks of chemical synthesis of sugar esters with good conversions/selectivity and reaction time ranging from 24 to 72 hours [7-11].

While enzymatic catalyzed reactions present important advantages over chemical catalysis, especially concerning green chemistry demands, some developments are still necessary [12]. One important characteristic of many enzyme-catalyzed reaction that prevents its use in large scale industrial process are the high dilutions needed in order to avoid product inhibition, leading to an economically inefficient processes. Despite all progress made on the biocatalyzed synthesis of sugar esters, in most cases the concentration of the starting material solution is still to dilute (mM range) to encourage an industrial application of this process [13].

But, one of the most important issues related to the synthesis of sugar esters is finding a solvent in which both reactants: carbohydrate and fatty acid can have a good solubility and the enzyme is still active. Several authors have tried to overcome the solubility issue by the use of protecting group strategies [14-16]. Recently, 


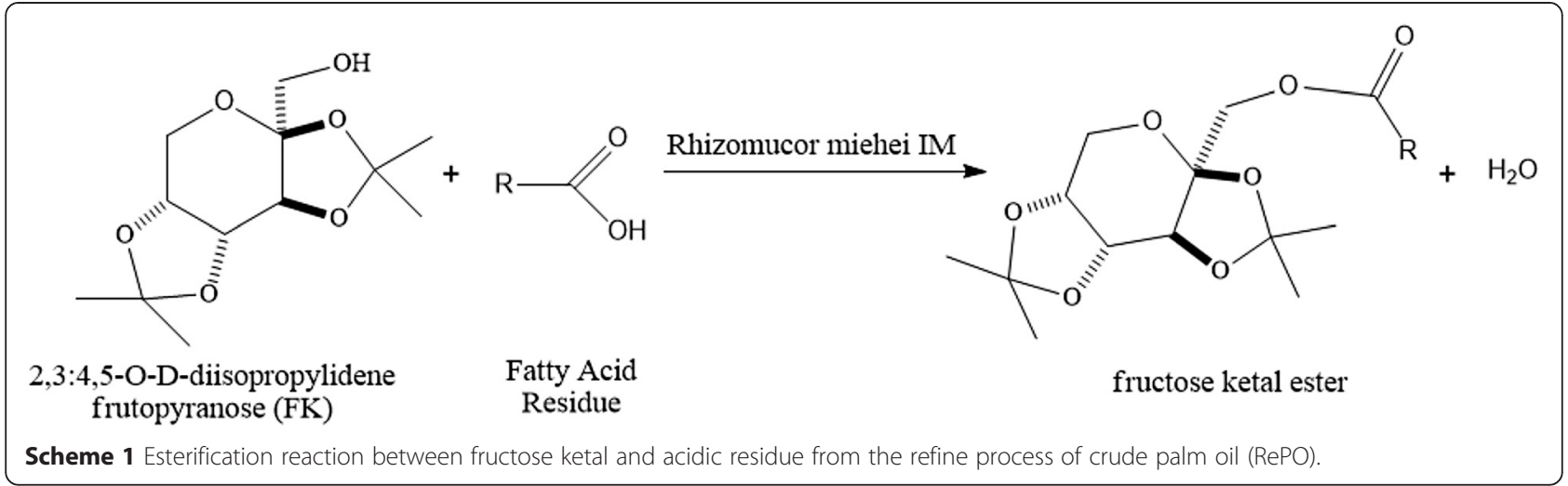

we reported the use of sugar ketal derivatives, on biocatalyzed reactions, as an alternative strategy in order to improve solubility of starting material [17].

Here in we report our efforts on the enhanced production of fructose ester by a biocatalyzed continuous flow approach. Aiming to add value to a residue from palm oil industry we have performed esterification reactions catalyzed by lipase between fructose ketal and free fatty acids derived from palm oil refining process (fatty acid residue) under continuous flow conditions at concentrations up to $0.5 \mathrm{M}$.

\section{Results and discussion}

In our continuous work on developing bio-catalyzed reactions under continuous-flow conditions, we decided to carry out the esterification between 2,3:4,5-O-D-diisopropylidene frutopyranose (FK) and acidic residue of palm oil refine process (RePO) under continuous flow conditions at increasing concentrations $(0.1,0.3$ and $0.5 \mathrm{M})$, using the commercial Rhizomucor miehei immobilized lipase, which is recognized in the literature by having remarkable esterification activity [18] (Scheme 1).

The packed bed was filled with the biocatalyst and the reaction performed with different flow rates according to the desired residence time. Different organic solvents were screened for this reaction being toluene, tertbutylmethyl ether and $p$-cymene the most promissing ones because had the best solubilization capacities, thereby used for further investigations. First, we investigated the conversions by using $0.1 \mathrm{M}$ solution of starting materials.

As presented in Table 1, all solvents tested showed high conversions at high residence times (24 minutes). However the results obtained for the reactions carried out in $p$-cymene presented lower conversions $(87.03 \% \pm 3.5)$ when compared with the other solvents and a dramatic decrease on conversion is observed when reducing the residence time from 24 minutes to 8 and 5.4 minutes. The decrease on conversion is less pronounced in
Toluene at a residence time of 8 minutes. But in a reaction time of 5.4 minutes the conversion decreased considerably (13.5\%). MTBE seems to be the best solvent choice, since even at high flow rates (short residence times, i.e. 5.4 minutes) high conversions are still observed (95.7 \pm 2.8 ), leading to a productivity of $34.3 \mathrm{mg} \cdot \mathrm{min}^{-1} \mathrm{~g}$ immob. enzyme ${ }^{-1}$.

In order to enhance the production of protected fructose ester we moved then for a more concentrated starting material solution $(0.3 \mathrm{M})$ and the results are summarized in Table 2.

In the reactions using $0.3 \mathrm{M}$ stock solution of substrates we can observe a different behavior of solvent effect. Excellent conversions were obtained in the reaction performed in toluene with very short residence times. In contrary to the observed on $0.1 \mathrm{M}$ solutions, MTBE has shown a significant decrease on conversion for reactions performed under residence times of 8 and 5.4 minutes $(21.55 \pm 2.50$ and $11.33 \pm 3.66$, respectivelly). The use of $0.3 \mathrm{M}$ stock solution with $p$-cymene as solvent lead to moderate results at high residence times. Under these conditions, toluene presented the best result leading to a productivity of $100 \mathrm{mg}$. $\mathrm{min}^{-1}$.g immob. enzyme ${ }^{-1}$.

Due the poor solubility of FK in $p$-Cymene at $0.5 \mathrm{M}$ was not possible performed a test with this solvent under continuous flow conditions at this concentration. At this time, only Toluene and MTBE were tested and results are presented on Table 3.

\section{Table 1 Esterification reaction between FK and RePO (0.1 M) catalyzed by Rhizomucor miehei IM under continuous flow conditions}

\begin{tabular}{llll}
\hline Residence time $(\min )$ & \multicolumn{3}{l}{ Conversion $(\%)^{\mathbf{a}}$} \\
\cline { 2 - 4 } & Toluene & MTBE & p-Cymene \\
\hline 24 & $98.2 \pm 1.0$ & $98.6 \pm 0.5$ & $87.0 \pm 3.5$ \\
8 & $87.6 \pm 3.0$ & $98.1 \pm 0.5$ & $18.5 \pm 2.2$ \\
5.4 & $13.5 \pm 2.8$ & $95.7 \pm 2.8$ & $2.6 \pm 4.3$ \\
\hline
\end{tabular}

abased on Lowry-Tinsley analysis. 
Table 2 Esterification reaction between FK and RePO ( $0.3 \mathrm{M})$ catalyzed by Rhizomucor miehei IM under continuous flow conditions

\begin{tabular}{llll}
\hline Residence time $(\boldsymbol{m i n})$ & \multicolumn{3}{l}{ Conversion $(\%)^{\mathbf{a}}$} \\
\cline { 2 - 4 } & Toluene & MTBE & $\boldsymbol{p}$-Cymene \\
\hline 24 & $99.91 \pm 0.08$ & $93.89 \pm 3.84$ & $57.7 \pm 5.1$ \\
8 & $99.69 \pm 0.12$ & $21.55 \pm 2.50$ & $30.8 \pm 3.7$ \\
5.4 & $93.03 \pm 2.60$ & $11.33 \pm 3.66$ & $33.3 \pm 2.5$ \\
\hline
\end{tabular}

abased on Lowry-Tinsley analysis.

At this substrate concentration $(0.5 \mathrm{M})$ the best results were obtained with high residence times for both solvents (24 minutes). A dramatic decrease on conversion is observed when reducing the residence time from 24 minutes to 8 minutes for both solvents, which can be explained as a substrate inhibition at such high concentration. Under these conditions the productivity obtained for the production of the protected fructose ester derived from the fatty acidic residue under continuous flow conditions is $40.3 \mathrm{mg}$ of ester. $\mathrm{h}^{-1}$.g of immob. enzyme $\mathrm{e}^{-1}$ and $40.2 \mathrm{mg}$ of ester. $\mathrm{h}^{-1} . \mathrm{g}$ of immob. enzyme $^{-1}$ for the reactions performed with MTBE and toluene, respectively. To the best of our knowledge such values have no precedent in the synthesis of sugars fatty acids esters. The recyclability of the enzyme source was also evaluated and was observed that the immobilized commercial enzyme from Rhizomucor miehei can be recycled for 6 times without change on reaction conversions.

The higher substrate concentration in the esterification reaction was also evaluated for other enzymes sources and the results are presented in Table 4.

We can see in the Table 3 the best results for reactions catalyzed by TL IM enzyme in 24 min of residence time performed with substrate solubilized in toluene (90.1\%). When compared the results of esterification catalyzed by RM IM lipase (Table 2) can be observed the greater conversion this enzyme (99.7\%) thus demonstrating that the best catalyst for the reaction. The protected fructose ester can be easily cleaved by several protocols already reported over literature [6].

Table 3 Esterification reaction between FK and RePO ( $0.5 \mathrm{M})$ catalyzed by Rhizomucor miehei IM under continuous flow conditions

\begin{tabular}{lll}
\hline Residence time $(\min )$ & \multicolumn{2}{l}{ Conversion $(\%)^{\mathbf{a}}$} \\
\cline { 2 - 3 } & Toluene & MTBE \\
\hline 24 & $99.76 \pm 0.24$ & $99.91 \pm 0.01$ \\
8 & $13.84 \pm 0.12$ & $22.25 \pm 3.07$ \\
5.4 & $12.71 \pm 3.66$ & $7.37 \pm 4.11$ \\
\hline
\end{tabular}

abased on Lowry-Tinsley analysis.
Table 4 Esterification reaction between FK and acid residue from palm oil refining process $(0.5 \mathrm{M})$ catalyzed by different immobilized enzymes under continuous flow conditions

\begin{tabular}{|c|c|c|c|}
\hline \multirow[t]{2}{*}{ Immob. Enz. } & \multirow{2}{*}{$\begin{array}{l}\text { Residence } \\
\text { Time } \\
\text { (min) }\end{array}$} & \multicolumn{2}{|c|}{ 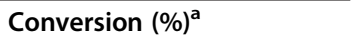 } \\
\hline & & Toluene & MTBE \\
\hline \multirow[t]{3}{*}{ Novozyme 435} & 24 & $52.39 \pm 0.87$ & $76.65 \pm 0.98$ \\
\hline & 8 & $44.96 \pm 3.77$ & $60.32 \pm 2.34$ \\
\hline & 5.4 & $29.21 \pm 3.21$ & $25.27 \pm 3.34$ \\
\hline \multirow[t]{3}{*}{ Lipozyme TL IM } & 24 & $90.18 \pm 0.87$ & $86.6 \pm 0.9$ \\
\hline & 8 & $28.8 \pm 3.24$ & $22.9 \pm 0.82$ \\
\hline & 5.4 & $17.9 \pm 5.43$ & $17.4 \pm 2.44$ \\
\hline \multirow[t]{3}{*}{ PS Amano IM } & 24 & $46.75 \pm 3.4$ & $62 \pm 4.3$ \\
\hline & 8 & $25.0 \pm 1.21$ & $34 \pm 2.19$ \\
\hline & 5.4 & $7.98 \pm 0.99$ & $12 \pm 1.36$ \\
\hline
\end{tabular}

abased on Lowry-Tinsley analysis.

\section{Conclusions}

In conclusion, we performed enzymatic synthesis of a secondary ester of protected fructose achieved with high substrate concentration and high percentage of conversion, by a simple method that add value to an acid residue of oil palm refining process. Continuous flow conditions allowed high product productivity in short reaction times.

\section{Methods}

\section{Chemicals and materials}

All reagents and immobilized enzymes were purchased from Sigma-Aldrich and used without further purification.

The acidic residue from the refine process of crude palm oil (RePO) was kindly provided by Agropalma Industry. The composition of the residue was determined through gas chromatography. The approximate composition is palmitic acid (44\%), oleic acid (42\%), and stearic acid (14\%).

\section{Synthesis of 2,3:4,5-O-diisopropylidene-D-frutopyranose} (FK) (2)

In a $2000 \mathrm{~mL}$ reactor was added $30 \mathrm{~g}(44.8 \mathrm{mmol})$ of sucrose and $400 \mathrm{~mL}$ of acetone being vigorously mechanically stirred at $5^{\circ} \mathrm{C}$ for $15 \mathrm{~min}$. Then, $16 \mathrm{~mL}$ of concentrate sulfuric acid $\left(\mathrm{H}_{2} \mathrm{SO}_{4}\right)$ was slowly added to the reaction mixture. The solution was kept under stirring for $150 \mathrm{~min}$. Subsequently, the reaction mixture was cooled $\left(0-10^{\circ} \mathrm{C}\right)$ in ice bath and neutralized with $50 \%$ $\mathrm{NaOH}(\mathrm{w} / \mathrm{v})$. The $\mathrm{pH}$ was adjusted with saturated sodium carbonate. The final mixture was filtered to remove the solids and subsequently, the solvent was evaporated under reduced pressure. The solid crude ketal was diluted with $400 \mathrm{~mL}$ of dichloromethane. A $0.5 \mathrm{M} \mathrm{H}_{2} \mathrm{SO}_{4}$ solution was added and stirred vigorously for $120 \mathrm{~min}$. The organic 
phase was separated and washed consecutively with sodium bicarbonate $\left(\mathrm{NaHCO}_{3}\right)$ and water and dried with anhydrous sodium sulfate $\left(\mathrm{Na}_{2} \mathrm{SO}_{4}\right)$. The solvent was evaporated under reduced pressure until obtaining a white solid, which was crystallized in hexane with $30 \%$ final yield after filtration through activated charcoal [19].

\section{Continuous flow reaction procedure}

An equimolar stock solution (tert-butylmethyl ether (MTBE), toluene or $p$-cymene) of 2,3:4,5-O-D-diisopropylidene frutopyranose (FK) and the RePO was prepared (the molarity of the residue was expressed in palmitic acid). The starting mixture was stirred for 5 min while the instrument Asia Flow Reactor was equipped with Omnifit column $(2.4 \mathrm{~mL})$ containing the immobilized lipase from R. miehei $(600 \mathrm{mg})$. The reaction parameters were selected on the flow reactor, and processing was started, whereby only pure solvent was pumped through the system until the instrument had achieved the desired reaction parameters and stable processing was assured. At this point, the inlet pipe of the flask was switched to HPLC bottle containing the prepared reaction mixture. After processing through the flow reactor, the inlet tube was dipped back into the flask containing respective pure solvent and processed in order to wash the system of any remaining reactant.

\section{Lowry-Tinsley method}

The conversion of the esterification reactions was measured by the adapted Lowry and Tinsley method [20]. In an eppendorf tube was placed $0.3 \mathrm{~mL}$ of reaction medium, $1 \mathrm{~mL}$ heptane, $0.3 \mathrm{ml}$ of $5 \%$ copper acetatepyridine solution ( $\mathrm{pH}$ 6) and stirred vigorously for 30 seconds. The supernatant was measured by spectrophotometer UV/715 nm visible wavelength. Each reaction was measured in triplicate and conversion calculations were based on the analytical curve with the fatty acid used. This methodology for determination of residual acid is aligned with the analytical chromatographic methods, being widely used.

\section{Statistical analysis}

A comparison of the data was performed using the software Statistica 6.0 (Statsoft, Inc., USA), through ANOVA followed by Tukey test, considering statistically significant when $\mathrm{p}<0.05$.

\section{Competing interests}

The authors declare that they have no competing interests.

\section{Authors' contributions}

All authors contributed equally in this work. All authors read and approved the final manuscript.

\section{Acknowledgements}

We thank CAPES (Coordenação de Aperfeiçoamento de Pessoal de Nível Superior) FAPERJ (Fundação de Apoio a Pesquisa do Estado do Rio de Janeiro) and CNPq (Conselho Nacional de Desenvolvimento Científico e Tecnológico).

\section{Author details}

${ }^{1}$ Biocatalysis and Organic Synthesis Group, Chemistry Institute, Federal University of Rio de Janeiro, Rio de Janeiro CEP 22941 909, Brazil. ²Faculdade de Farmácia, Federal University of Rio de Janeiro, Rio de Janeiro CEP22941909, Brazil.

Received: 22 October 2014 Accepted: 17 March 2015 Published online: 07 May 2015

\section{References}

1. Chang SW, Shaw JF. Biocatalysis for the production of carbohydrate esters. New Biotechnol. 2009;26:109-16.

2. Shi Y, Li J, Chu Y-H. Enzyme-catalyzed regioselective synthesis of sucrosebased esters. Chem Technol Biotechnol. 2011;86:1457-68.

3. Flores MV, Engasser JM, Halling PJ. Dissolution kinetics of crystalline -glucose in 2-methyl 2-butanol. Biochem Eng J. 2005;22:245-52.

4. Baker IJA, Matthews B, Suares H, Krodkiewska I, Furlong DN, Grieser F, et al. Sugar fatty acid ester surfactants: structure and ultimate aerobic biodegradability. J Surfact Deterg. 2000;3:1-11.

5. Soultan S, Ognier S, Engasser J-M, Ghoul M. Comparative study of some surface active properties of fructose esters and commercial sucrose esters. Colloids Surf A: Physicochem. 2003;227:35-44.

6. Yan YC, Bornscheuer UT, Stadler G, Lutz-Wahl S, Otto RT, Reuss M, et al. Production of sugar fatty acid esters by enzymatic esterification in a stirredtank membrane reactor: optimization of parameters by response surface methodology. J Am Oil Chem Soc. 2001;78:147-52.

7. Neta NDAS, Dos Santos JCS, Sancho SDO, Rodrigues S, Gonçalves LRB, Rodrigues $L R$, et al. Enzymatic synthesis of sugar esters and their potential as surface-active stabilizers of coconut milk emulsions. Food Hydrocoll. 2012;27:324-31.

8. Therisod M, Klibanov AM. Facile enzymatic preparation of monoacylated sugars in pyridine. J Am Chem Soc. 1986;108:5638-40.

9. Therisod M, Klibanov AM. Regioselective acylation of secondary hydroxylgroups in sugars catalyzed by lipases in organic-solvents. J Am Chem Soc. 1987:109:3977-81.

10. Riva S, Therisod J, Kieboom APG, Klibanov AM. Protease-catalyzed regioselective esterification of sugars and related-compounds in anhydrous dimethylformamide. J Am Chem Soc. 1988;110:584-9.

11. Ikeda I, Klibanov AM. Lipase-catalyzed acylation of sugars solubilized in hydrophobic solvents by complexation. Biotechnol Bioeng. 1993;42:788-91.

12. Rousseau D, Marangoni AG. The effects of interesterification on the physical properties of fats. In: Narine SS, Marangoni AG, editors. Physical properties of lipids. New York: Marcel Dekker; 2002. p. 479-564.

13. Pauly G, Engasser J, Ghoul M. Method for enzymatic synthesis of sucrose esters. U. S. Patent: Laboratoires Serobiologiques (Societe Anonyme), France. US 6,355,455, 2002 March 12.

14. Ward OP, Fang JW, Li ZY. Lipase-catalyzed synthes, is of a sugar ester containing arachidonic acid. Enzyme Microb Technol. 1997;20:52-6.

15. Fregapane G, Sarney DB, Vulfson EN. Enzymic solvent free synthesis of sugar acetal fatty acid esters. Enzyme Microb Technol. 1991;13:796-800.

16. Gao CL, Whitcombe MJ, Vulfson EN. Enzymatic synthesis of dimeric and trimeric sugar-fatty acid esters. Enzyme Microb Technol. 1999;25:264-70.

17. Sutili FK, Ruela HS, Leite SGF, Miranda LSM, Leal ICR, De Souza ROMA. Lipase-catalyzed esterification of steric hindered fructose derivative by continuous flow and batch conditions. J Mol Catal B Enzym. 2013;85-86:37-42.

18. Rodrigues RC, Fernandez-Lafuente R. Lipase from Rhizomucor miehei as an industrial biocatalyst in chemical process. J Mol Catal B Enzym. 2010;64:1-22.

19. Ferreira VF, Perrone CC. Sacarose no laboratório de química orgânica de graduação. Quim Nova. 2001;24:905-7.

20. Lowry RR, Tinsley IJ. Rapid colorimetric determination of free fatty acids. J Am Oil Chem Soc. 1976;53:470-2. 